\title{
Fostering Scientific Literacy and Critical Thinking in Elementary Science Education
}

\author{
Rui Marques Vieira $\cdot$ Celina Tenreiro-Vieira
}

Received: 30 April 2014 / Accepted: 13 November 2014 /Published online: 30 December 2014

(C) Ministry of Science and Technology, Taiwan 2014

\begin{abstract}
Scientific literacy (SL) and critical thinking (CT) are key components of science education aiming to prepare students to think and to function as responsible citizens in a world increasingly affected by science and technology (S\&T). Therefore, students should be given opportunities in their science classes to be engaged in learning experiences that promote SL and CT, which may trigger the need to build and develop knowledge, attitudes/values, thinking abilities, and standards/criteria in an integrated way, resulting in their ability to know how to take responsible action in contexts and situations of personal and social relevance. This paper reports on a study to design, implement, and assess science learning experiences focused on CT toward SL goal. Results support the conclusion that the learning experiences developed and implemented in a grade 6 science classroom had a significant influence on the students' CT and SL. Within this elementary school context, the theoretical framework used appears to be a relevant and practical aid for developing learning experiences that promote CT/SL and in supporting teaching practices that are more in line with the goals of critical scientific literacy.
\end{abstract}

Keywords Critical thinking · Elementary science education · Scientific literacy

Today's knowledge-based societies reflect a rapid evolution of science and technology (S\&T) and a need for an all-inclusive science education that begins from the early years. All students, not only those who wish to pursue a career in science or technology, should benefit from the science education provided, which includes understanding the scientific dimension of phenomena and events; critical appreciation of the potentialities and limitations of science, its role in society, and its contribution to citizenship; and development of critical thinking, oral communication, and writing skills

R. M. Vieira

Department of Education, University of Aveiro, 3810-193 Aveiro, Portugal

R. M. Vieira $(\bowtie) \cdot$ C. Tenreiro-Vieira

Research Centre for Didactics and Technology in Teacher Education, University of Aveiro, Aveiro, Portugal

e-mail: rvieira@ua.pt 
(BSCS, 2008). Several recent international science education reforms have included scientific literacy (SL), science practices, critical thinking (CT), and socioscientific issues as learning outcomes (National Research Council [NRC], 2012; Rocard et al., 2007). However, few reforms provide an operational definition of SL that includes CT and that is practical and useable by elementary science teachers to guide their planning, classroom teaching, and assessment practices.

This study, which is part of an ongoing program of inquiry, involved the development of a framework and an action research plan that documented a design-implementation-evaluation process of learning experiences focused on CT and SL. The framework that involved the CT and SL components (Vieira, Tenreiro-Vieira \& Martins, 2011) guided the development and enactment of lessons within a grade 6 classroom.

\section{Background}

Harlen (2010) suggested that science education should enable every individual to take an informed part in decisions and appropriate actions that affect their well-being and the welfare of society and the environment. This implies a broad understanding of key science ideas in conjunction with the development of scientific skills and attitudes relevant to students' lives during and beyond their school years so that they can productively adapt and operate in a knowledge-driven society. Participation as active citizens and agents of social cohesion in a pluralistic, scientific, and technologically advanced democratic society requires more than being able to complete tasks imposed externally. It also requires being able to (a) extrapolate from what has been learnt; (b) apply built knowledge and thinking skills to interact with others, communicating positions and counter-arguments effectively; (c) participate in problem-solving and decision-making processes; and (d) form rational opinions about sciencebased issues to achieve sustainable development in modern societies (International Council for Science [ICSU], 2011).

\section{Current International Science Education Reforms}

International science education documents have stressed a science-technology-society (STS) approach in order to promote SL in close connection with CT (Aikenhead, 1992; Vieira et al., 2011). Scientific literacy_-by emphasizing scientific knowledge (knowledge of and about science) and the use of that knowledge in different contexts and situations in conjunction with scientific ways of thinking - provides citizens with the necessary tools to engage with science critically, reinforcing a more humanistic culture that is based on rational thinking (Harlen, 2010; ICSU, 2011; Osborne \& Dillon, 2008; Rocard et al., 2007). Without this preparation, people are likely to make decisions and choices with implications for themselves and others that are based on opinion, experience, or personal interest or based on information or the beliefs of others (ICSU, 2011). Many countries have promoted science curricula projects oriented toward SL where CT emerges as a prominent component. 


\section{United States of America (USA)}

Highlighted among the curricular proposals for science teaching in a literacy perspective in the USA are the Project 2061: Science for All Americans and Benchmarks for Science Literacy (American Association for the Advancement of Science, 1990, 1993), National Science Education Standards (NRC, 1996), and A Framework for K-12 Science Education: Practices, Crosscutting Concepts, and Core Ideas (NRC, 2012). The framework document describes the major science and engineering practices, crosscutting concepts, and disciplinary core ideas that all students should have acquired by the end of grade 12 so as to engage in public discussions on science-related issues and to be critical consumers of scientific information related to their everyday lives. Based on this vision, the Next Generation Science Standards (NGSS Lead States, 2013) established the standards designed to prepare students for college, career, and citizenship.

\section{Australia}

Hackling, Goodrum \& Rennie (2001) highlighted that the basic purpose of science education in Australian compulsory education is to develop students' scientific literacy, which has a critical stance. They argued that SL is a priority for all citizens as it helps them to (a) become interested in and understand the world around them; (b) engage in scientific discussions; (c) be skeptical and question statements made by others on issues that involve science; (d) be able to identify questions for scientific investigations, to explain scientific phenomena, and to draw evidence-based conclusions about sciencerelated issues; and (e) make informed decisions on the environment, their health, and welfare.

\section{Canada}

The Pan-Canadian Protocol for Collaboration on School Curriculum developed the Common Framework of Science Learning Outcomes, K to 12 (Council of Ministers of Education of Canada, 1997) that has an implied SL-CT perspective. This framework is guided by the vision that all Canadian students will have an opportunity to develop scientific literacy, which can serve as a strong future for them. It established four foundation statements that delineated critical aspects of students' scientific literacy: (a) science, technology, society, and environment (STSE); (b) skills required for scientific and technological inquiry, for solving problems, for communicating scientific ideas and results, for working collaboratively, and for making informed decisions; (c) knowledge, understandings, and applications of scientific concepts to interpret, integrate, and extend their knowledge; and (d) attitudes that support the responsible acquisition and application of scientific and technological knowledge to the mutual benefit of self, society, and the environment.

\section{European Union}

The project Beyond 2000: Science Education for the Future (Millar \& Osborne, 1998) argued in favor of a new vision for science education in Europe and presented ten 
recommendations. The first recommendation was that science curriculum (from 5 to 16 years of age) should be seen, first and foremost, as a promoter of general scientific literacy. Consequently, the report of Rocard et al. (2007) stressed that, in providing all citizens with both scientific literacy and a positive attitude toward science, the key point is equipping every citizen with the skills needed to live and work in the knowledge society by giving them the opportunity to develop CT and scientific reasoning thereby enabling them to make well-informed choices. Students should be able to (a) develop a basic understanding of mathematics and science to understand the issues and make informed choices; (b) acquire more knowledge, when necessary, whether for personal interest or for professional reasons; (c) make judgments on scientific ideas and procedures; (d) assess the reasons fundamental to making decisions that have to be made in everyday contexts; (e) understand and respond critically to reports presented by the media on social problems with underlying scientific issues; and (f) express a personal point of view on issues that encompass science and are in public debate in addition to becoming actively involved.

\section{England}

The current National Curriculum in England (Department for Education, 2013) aims to ensure that students, from an early age, develop essential aspects of the knowledge, methods, processes, and uses of science and other disciplines. It emphasizes that science provides opportunities for student to (a) develop their scientific vocabulary, articulating scientific concepts clearly and precisely in making their thinking clear and (b) work scientifically, developing secure understanding of key scientific knowledge and concepts and thinking skills through the involvement in scientific enquiry, and using a variety of approaches to answer relevant scientific questions. These approaches include observing over time; identifying, classifying, and grouping; investigating (controlled investigations); and researching using secondary sources. It should be noted that the development of the curriculum was based on comparative curricula studies of countries with high performance in international assessments (e.g. Trends in International Mathematics and Science Study and Programme for International Student Assessment [PISA]). The comparative studies showed that the main purpose of science education was to prepare students to continue their studies and ensure that all students are scientifically literate adults able to act responsibly and as informed individuals (Department for Education, 2011).

\section{Finland}

The National Core Curriculum for Basic Education in Finland (Finnish National Board of Education, 2004) emphasizes that basic education must provide an opportunity for diversified growth and learning so that students are able to build the knowledge and skills they need in order to continue their studies and develop a democratic society as concerned citizens. The curriculum assumes a sustainable development perspective in which it is stressed that science teaching must stimulate pupils to (a) care for their environment and act responsibly toward it and (b) make choices that promote individual and collective health and well-being. 


\section{Portugal}

Portuguese curricular documents have identified SL as the main goal of science education, highlighting the importance of the development of scientific knowledge and thinking abilities, such as CT and reasoning, to deal with socioscientific issues (Vieira et al., 2011). The latest science education curriculum guidelines identify the knowledge and skills that students must develop to continue their education and to meet the needs of society (Ministério da Educação e Ciência [Ministry of Education and Science], 2013).

The commonalities across these international science education reforms are the broadening perspective of considering both mainstream SL-literacy for citizenship — and pipeline SL - further studies and future careers in science and engineering. Despite the restructuring of science curricula, international studies focused on SL suggest that, depending on the country, between one- and two-thirds of the population does not demonstrate a minimum level of skills considered essential to engage in further learning and to function in modern economies and societies increasingly dependent on the use of knowledge (Rocard et al., 2007). Similarly, science that has been taught in school has failed to help students become interested in science (Osborne \& Dillon, 2008; Rocard et al., 2007).

As indicated by the high number of young people who experience social inequalities or learning difficulties or who leave school without a diploma and the high number of functionally illiterate adults, educational authorities have placed an increasing emphasis on changes to the curriculum. Oates (2010) noted that the national curriculum of a country cannot be considered isolated from other vital factors that affect the educational system (e.g. teacher education and professional development, learning activities and didactic resources, and teaching practices). All elements of the school system interact, and they should be constantly adjusted in order to be consistent with the goals stated in the curriculum (Department for Education, 2011). Therefore, it is crucial to sustain the development of resources, teaching strategies, and learning experiences for science education and provide professional development opportunities necessary for teachers to adapt and transform their practices (Osborne \& Dillon, 2008).

The Organisation for Economic Co-operation and Development (OECD) policy report entitled Evolution of Students' Interest in Science and Technology Studies (OECD, 2006b) stressed that traditional science teaching methods have a negative impact on students' interest in science and on the development of positive attitudes toward learning science. This report noted the uncomfortable situation for some teachers in the early years of schooling who are requested or required to teach subjects (i.e. science) in which they lack self-confidence or knowledge. This situation often leads them to resort to a blackboard-and-white-chalk approach with which they feel most comfortable and to avoid research-based approaches that require a deeper and integrated understanding of science, resulting in an emphasis on the memorization of factual information.

\section{Scientific Literacy}

Scientific literacy has been identified and recognized as a goal of science education. Despite this, there is no consensus on the meaning of the term 
scientific literacy. Science researchers and educators as well as various organizations have developed rationales and highlighted characteristics, mainly in terms of knowledge and skills, expected of a scientifically literate person. The NRC (1996) defined SL as "the knowledge and understanding of scientific concepts and processes required for personal decision making, participation in civic and cultural affairs, and economic productivity" (p. 22). Each individual should be able to (a) ask or find answers to questions arising from their own curiosity regarding everyday experiences; (b) describe, explain, and predict natural phenomena; (c) interpret newspaper articles about science in the media and engage in public social discussion about the validity of the conclusions presented and methods used; (d) identify scientific issues underlying local and national decisions; (e) take and express positions based on scientific and technological knowledge; (f) assess scientific information based on the credibility of the sources and the validity of methods used to generate it; and ( $\mathrm{g}$ ) evaluate arguments based on scientific evidence.

The PISA framework defined SL as the ability to use scientific knowledge and processes not only to understand the natural world but also to participate in decisions about it and the changes therein made by human activity (OECD, 2006a, 2009). More specifically, PISA considers that SL aids individuals in identifying scientific questions; acquiring new knowledge; explaining scientific phenomena and drawing conclusions based on evidence about science-related issues; understanding the characteristic features of science as a form of human research and knowledge; being aware of how S\&T shape the material, intellectual, and cultural environments; and encouraging involvement in science-related issues and with scientific ideas as a reflective citizen.

Harlen (2006) stressed that being scientifically literate means being able to appreciate and understand the impact of S\&T in everyday life, assessing risks and benefits of scientific and technological advances; using ideas, concepts, and scientific processes in decision making; and having an open-mindedness to accept alternative viewpoints that are based on scientific evidence. Hofstein, Eilks \& Bybee (2011) argued for increased emphasis on STS education and a stronger inclusion of societal issues in science education:

Dealing with issues that are socially relevant and which are actually discussed is relevant to the lives of students in present society. Skills developed along these lines will be important for students' participation in societal debates concerning the development of their future as scientifically literate citizens. (p. 1464)

Science education with an STS orientation that emphasizes the interrelationships of scientific concepts and real-life phenomena can better serve students (Vieira et al., 2011).

The PISA definition and STS context assume that students will acquire and apply scientific knowledge where rational thinking and relating evidence and conclusions are seen as pivotal to all citizens in order to make informed and sustainable decisions about courses of action that affect life on a personal, social, and global level. Fundamental in such literate use of empirical argumentation is the ability of individuals to communicate effectively; otherwise, they will not be able to engage and have a voice in public debates about SSI. 
Roberts (2007) defined the ideologies of SL on a continuum between two extremes: vision I and vision II. Vision I is scientist-centered and focused on decontextualized science subject matter; vision II is student-centered and context-driven, with the aim to enculturate students into their local, national, and global communities (Aikenhead, 2007). Yore, Pimm \& Tuan (2007) suggested that there are two interacting senses of contemporary disciplinary literacy: the fundamental sense and the derived sense.

The fundamental sense subsumes abilities, emotional dispositions, and information communication technologies as well as communication (speaking, listening, reading, writing, representing, interpreting), while the derived sense subsumes the content goals regarding understanding the big ideas of science, the nature of science, scientific inquiry, technological design, and the relationships among STSE. (p. 568)

Recently, science education researchers are mentioning a vision III. This vision emphasizes SL as being the combination of abilities, skills, dispositions, and knowledge to engage STSE issues and debates (Yore, 2012; Yore et al., 2007). Based on the work of Yore and collaborators, Lin (2014) identified three interacting clusters involved in vision III: fundamental literacy in science (metacognition, CT, habits of mind, language, information communication technologies), understanding of the big ideas (core ideas, crosscutting concepts, nature of science, scientific inquiry, technological design), and fuller participation in the public debate about socioscientific issues resulting in informed decisions and sustainable actions.

\section{Critical Thinking}

Several definitions for CT have been proposed. Ennis (1987) suggested that CT is reasonable, reflective thinking that is focused on deciding what to believe or do; it involves affective dispositions and cognitive abilities. CT dispositions reflect a critical spirit consisting of a trend, commitment, or inclination to act critically then applying CT abilities attending to CT criteria and standards. These dispositions include trying to be well informed, using and mentioning credible sources, searching for reasons and alternatives, having an open mind, and trying to be as precise as the issue permits. Ennis identified several cognitive abilities that contribute to rationally deciding what to do or what to believe: focusing on one question, asking and answering clarification and/or challenging questions, analyzing arguments, assessing the credibility of the sources, making and assessing observations, making and assessing inferences (deductions, inductions, and value judgments), deciding a course of action, and interacting with others. The use of standards as criteria for judging the quality of thought is required in order to ensure the effective use of such abilities.

Hatcher \& Spencer (2000) suggested that CT is thought which seeks to achieve judgment after the alternatives have been truly assessed, respecting the arguments and evidence available. Therefore, CT can be an open process given that sometimes the arguments and the evidence available may be insufficient or inappropriate. In this case, unless the individuals are forced to make a 
choice, they should not make a judgment before having done research that provides the necessary evidence to support or rebut an argument. Furthermore, CT should include the assessment of alternatives or different points of view before making a decision or judgment. This assessment should be honest, which implies seeking to act impartially and with objectivity, include all available alternatives, present each alternative in its most favorable light, use the same criteria used to reject a given alternative to all positions in order to assess each one with the same criteria and rationality, and be willing to change a position in light of new arguments or evidence.

Scriven \& Paul (2007) defined CT as a disciplined intellectual process that actively and effectively conceptualizes, applies, analyzes, and/or assesses information obtained from different sources (e.g. observation, experience, communication) as a guide to belief and action. The critical thinker systematically and intentionally develops attitudes, becomes aware of elements of thought, applies intellectual criteria to thought, and assesses the effectiveness of the thinking process while taking into account the purpose and intellectual criteria. CT is based on intellectual criteria (e.g. clarity, accuracy, consistency, and valid evidence) that are used in the analysis of elements of thought (e.g. problems or questions under consideration, assumptions, conclusions, implications and consequences from alternative viewpoints, and different frameworks of reference). Ford \& Yore (2012) suggested that CT can be considered the deliberate process of determining what to believe or do about a worthy challenge. This means that the critical thinker needs to examine the text contents or arguments in mass media reports and then evaluate the evidence behind a claim, belief, or action that will allow them to determine the validity, reliability, and authenticity of the information and how well it supports the claim.

Ennis \& Millman (1985) developed the Cornell Critical Thinking Test based on prior conception, which is still considered to be one of the most valid measures of CT. The test incorporates five aspects of CT (i.e. induction, deduction, observation, credibility of statements made by others, and assumption identification) but does not assess value meaning, value judgment, CT attitudes, or values.

\section{Purpose and Research Questions}

Classroom teachers, namely elementary school teachers, need fully developed resources and procedures to implement desired innovative ideas. Assuming the relevance of developing learning experiences and didactic resources that support teaching practices congruent with SL as the first goal of science education, this study was conducted in order to conceive, implement, and assess the influence of learning experiences focused on CT aimed at SL in science education during compulsory education. The following research questions guided the design and enactment of the study:

1. Do the learning activities developed contribute to the improvement of students' critical thinking level?

2. Do the learning activities developed contribute to the improvement of students' scientific literacy level? 


\section{Development of the Learning Experiences}

\section{A Framework for Scientific Literacy/Critical Thinking}

Among the different conceptualizations of SL and CT, there is wide interdependence and overlap. Yore et al. (2007) suggested CT was one of the components in the fundamental sense of SL, where CT was defined as deciding what to believe or do about a challenge. When facing a worthwhile challenge, issue, or problem, a scientificliterate person will make a judgment about what to believe or do and will justify the claim/judgment based on accurate evidence and rational criteria. This makes CT critical in the construction of science understandings and the applications of this understanding to STS issues, problem solving, and decision making.

Norris \& Ennis (1989) suggested that CT involves problem solving and decision making because it occurs in a problematic context and/or an interacting context where it is necessary to rationally decide what to do or believe. The processes and practices of science help to make judgments in problem solving within interactive situations. Following this idea, some abilities arise at the intersection of SL and CT; for example, assessing the credibility of sources, assessing the available evidence and going beyond their immediate and apparent value; arguing, analyzing, and assessing arguments; identifying fallacies and assumptions underlying a given position; and considering, comparing, and weighing alternatives. Similarly, the SL-CT intersection contains dispositions such as the search to be well informed, respect for the use of evidence, skepticism in the assessment of assertions, intellectual honesty, and open-mindedness.

Collectively, the definitions of SL and CT and the unique and shared attributes of SL and CT served as design principles for the SL-CT framework. Figure 1 highlights the components or dimensions common to SL and CT emerging from perspectives of various authors and organizations on these concepts (adapted from Tenreiro-Vieira \& Vieira, 2011).

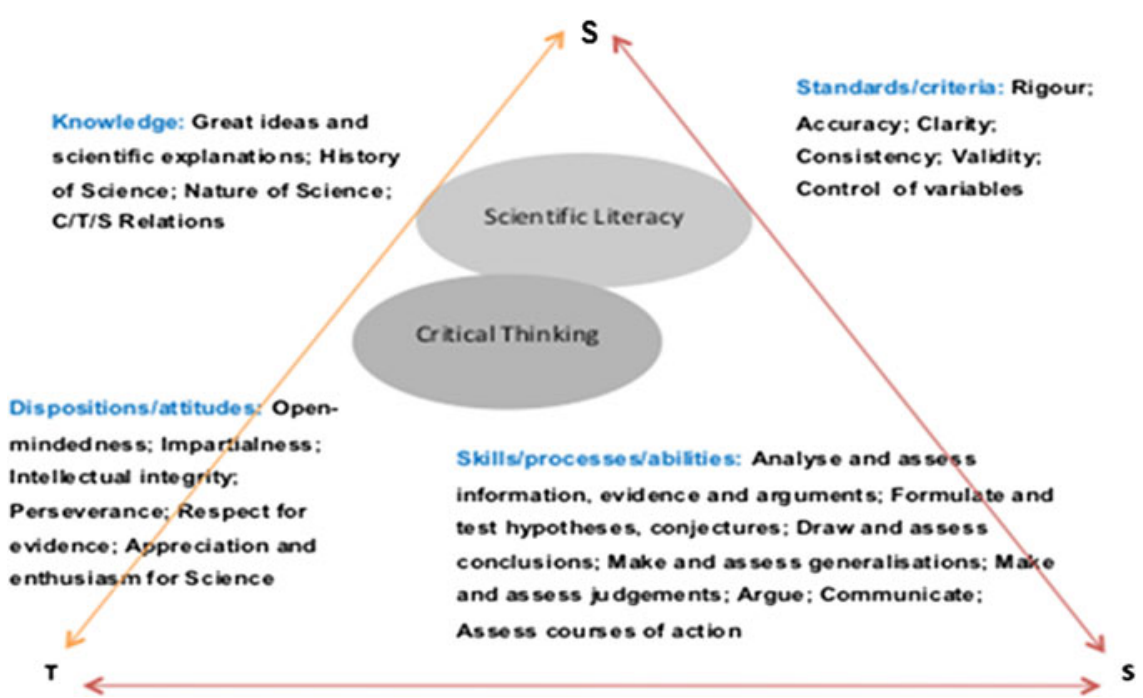

Fig. 1 Intersection of components common to SL and CT (adapted from Tenreiro-Vieira \& Vieira, 2011) 
In this context, science and technology are seen as socially contextualized human activities that influence each other. Science (S) as an inquiry-focused enterprise is mainly concerned with understanding of the natural world and how the natural world works; observable physical evidence is the basis of that understanding and related explanations stressing physical causality. Technology (T) is concerned with developing knowledge and designing processes in response to human needs and societal problems. Therefore, $\mathrm{S}$ and $\mathrm{T}$ influence and can be influenced by society (S). This framework can be used to develop resources and science activities that allow students to experience situations of action and participation, which may stimulate them to develop or reconstruct knowledge, abilities, dispositions, and standards. The integrated network constitutes a foundation for responsible action taken in contexts of personal, professional, or social relevance. The use of CT in such situations should appear closely linked to scientific practices and to the efficient and rational use of scientific knowledge-mainstream SL for citizenship. This is fundamental, particularly in real-life situations and contexts related to S\&T that affect humanity and in which the public has or should have a legitimate voice in participatory action. Such participatory action may involve questioning arguments from different positions, keeping in mind the validity of the evidence and the credibility of sources used in its construction. This S-T-S framework integrates components from the fundamental and derived senses of SL vision III (Yore, 2012; Yore et al., 2007).

\section{Design and Construction}

The SL-CT framework and the Portuguese curriculum guidelines for the teaching of physics and natural sciences in elementary schools defined the context of this study. CT in science is governed by criteria and standards: accuracy, clarity, consistency, credibility of sources, control of variables, and validity of inferences. The learning experiences were designed to be used in a grade 6 classroom with 11-12-year-old students.

First, we identified science topics from the grade 6 Portuguese curriculum guidelines that would be the conceptual focus of the learning experience. Problem-questions and learning situations with a CT/SL orientation were identified for each topic based on the framework. Second, these activities were operationalized through the development of questions that required the construction of knowledge and development of thinking abilities to be mobilized for informed and rational action. The Appendix displays examples of the learning experiences developed and shows the integration of the conceptual area and CT/SL elements or aspects of the CT/SL framework.

\section{Methodology}

The study followed a mixed-methods approach anchored in action research, which we considered to be the most feasible and coherent approach to focus on the curriculum innovation issues that were central to the design, production, implementation, and assessment of the learning experiences developed. Coutinho (2011) described action research as a multi- or mixed-methodological research plan that is characterized as 
being situational, interventional, participatory, and self-assessing with a primary goal focused on innovation and change. The intention of this study's intervention was to understand and then transform the science teaching practices in the context of a 6th year class in an urban public school composed of the second (grades 5 and 6) and third (grades 7, 8, and 9) cycles of Portuguese basic education.

\section{Context and Participants}

The selection of this class, as the context of action research, stems from its science teacher's (a co-author of this paper) involvement in the development and evaluation of the learning experiences as a teacher-researcher (TR). Thus, conditions for the implementation of the learning activities were created, respecting the principles underlying their design and production. The class consisted of 22 students, 13 girls and 9 boys, aged 11 to 12 years. The socioeconomic level of the students' families ranged from medium to medium high, and the educational qualifications of parents ranged from grade 6 to $\mathrm{PhD}$ degree. Similarly, parents' professions were diverse, including housekeeper, technician, nurse, and teacher.

\section{Implementation and Assessment}

Implementation of the learning activities occurred in the science lessons of the 6th year class. In each science lesson, students performed and then discussed the learning experiences under the guidance of the TR throughout the school year (i.e. November to May). Each learning experience provided all students a guide containing explicit requests and questions. The TR organized the classroom instruction into three phases: presentation of the learning experience and delivery of the respective guide to the students; development of work by students, responding to requests and questions in the guide; and summary and evaluation of the work.

In the first stage, the TR presented the situation and promoted a comprehensive reading of the students' guide by formulating questions that appeal to CT abilities such as What are the words or phrases that need clarification regarding the definition. Why? Summarize the situation presented. In the second stage, students answered the requests and questions in their guide; for example, in the debate case, they were involved in the preparation and realization of the debate. During the debate preparation, students were asked to search for, select, and assess the credibility of sources of information; to seek, compare, and weigh reasons for and against a particular point of view; and to consider implications and alternatives. During the debate implementation, students were invited to present and defend their point of view about the focus questions and to question and rebut the opposing point of view. During this lesson stage, the TR encouraged students to progress with their work by formulating questions such as What are your options? What if [...]? This happens every time or just sometimes? What happens in the cases analyzed? How did you justify the relationships you have set? Is this thesis consistent with the facts/evidence presented? Is the information used relevant, valid, and sufficient to support 
the thesis? Is there another plausible explanation for the observations made? In the third stage, the TR asked questions to promote student's CT abilities that focused on summarizing and making a value judgment about the work developed. Data were collected during and after the implementation of the learning experiences as a normal part of formative and summative assessment.

Data Collection and Analysis

The several data collection techniques employed (i.e. tests, observations, and instructional documents) allowed the information obtained to be triangulated and to explore their validity. The Cornell CT test (Ennis \& Millman, 1985), which had been translated and validated for use in Portuguese classrooms (Vieira, 1995), and an SL test composed of items translated and adapted from PISA tests (OECD, 2006b) and from the Australian National Assessment Program-Science Literacy Year 6 (Ministerial Council on Education, Employment, Training and Youth Affairs, 2006) were used to assess the influence of the learning experiences on CT and SL, respectively. These tests were designed and validated for this study and were used with the participating students at the beginning (pretest) and at the end (posttest) of the instruction.

\section{Cornell CT Test}

The Cornell CT test (level X) consists of 76 multiple-choice items organized in four parts. Following the standardized instructions, the test was given in two 45-min periods; the first two parts were conducted on the first day and the remaining two parts on the second day. Scoring of the test followed established procedures where the results are the difference between the number of correct answers and half of the number of incorrect answers.

\section{SL Test}

The final version of the SL test consisted of 20 items (multiple-choice, shortanswer, open-ended extended) and was administered during a 90-min lesson. These items were organized in units; they were based on a text or a chart, table, or diagram and illustrated a concrete, real-world situation that required students to mobilize scientific knowledge and CT abilities. The items reflected the Portuguese science curriculum for grade 6 regarding issues such as life, environment, and health.

Scoring of the test results was the sum of the points obtained in each item, with a maximum score of 100 points. The score of each item's response resulted from the application of the criteria established and was expressed as an integer number. In multiple-choice items, the total score (5 points each) was assigned only to responses with the correct option; all other responses received zero points. The short-answer items were scored according to a rubric where fully correct answers received 10 points and partially correct answers 5 points. The open-ended extended items (15 points each) were scored according to criteria organized by level of performance that considered coherent organization 
and appropriate scientific language content, each corresponding to a given score. In response performance level 1 (15 points), three content aspects were required; in level 2 (10 points), two content aspects were required; and in level 3 (5 points), either one content aspect was required or two to three aspects were presented but with failure of coherence in the content and organization and failure in the application of scientific language.

\section{Qualitative Data}

Observations made on the students' reactions and the teacher-student and peer interactions within the classroom were recorded to clarify and enrich the understanding of the quantitative test results. Similarly, the students' written works done in the context of the learning experiences developed were collected.

\section{Data Analysis}

Exploratory and confirmation analyses were used to relate the students' scores on the CT and SL tests. The first analysis included the use of descriptive statistics, which were presented in tables and complemented with graphical methods. Given that the preliminary analysis of data revealed normal distributions of the CT and SL scores, then the second analysis used $t$ tests (paired samples $t$ test) to compare pretest and posttest means.

Documents resulting from observation records and students' written products were analyzed using content analysis based on exploratory procedures. This involved organizing the documents and reading them several times; constructing indicators and defining units, which allowed descriptions of pertinent characteristics of the content; and searching for patterns and regularities in the data and interpreting them in light of the theoretical framework (Coutinho, 2011).

\section{Results}

The two research questions were related to the influence of the learning experiences developed on the students' CT and SL levels. Descriptive statistics and data distribution characteristics on the students' CT and SL pretest and posttest scores are summarized in Table 1 . Inspection of the data revealed that the average and median CT posttest scores were higher than the average and median CT pretest scores. Likewise, the average and median SL posttest scores were higher than the average and median SL pretest scores.

Comparison of the CT pretest and posttest averages was obtained with a $t$ test that revealed a significant improvement, $t=4.68, p<0.001$, indicating that the posttest average was higher than the pretest average. Comparison of the SL pretest and posttest averages revealed a significant improvement, $t=2.84$, $p<0.01$, also indicating a higher posttest than pretest average. Thus, the averages obtained by the students for both CT and SL were significantly higher after the implementation of the learning experiences. Within the limitations of a 
Table 1 Descriptive statistics for students' scores on the critical thinking and scientific literacy pretests and posttests

\begin{tabular}{lrrrrr}
\hline \multirow{2}{*}{ Statistic } & \multicolumn{2}{c}{ Critical thinking } & & Scientific literacy \\
\cline { 2 - 3 } \cline { 6 - 7 } & Pretest & Posttest & & Pretest & Posttest \\
\cline { 6 - 7 } Average & 25.93 & 35.98 & & 70.35 & 81.35 \\
Median & 27.25 & 35.00 & & 69.00 & 79.50 \\
Standard deviation & 9.54 & 8.38 & & 15.64 & 15.42 \\
Variance & 91.16 & 70.20 & & 244.55 & 237.92 \\
Minimum & 12.50 & 22.00 & & 31.00 & 46.00 \\
Maximum & 47.00 & 51.50 & & 98.00 & 100.00 \\
1st quartile & 17.37 & 29.25 & & 61.00 & 73.25 \\
3rd quartile & 33.87 & 43.62 & & 82.75 & 95.75 \\
Asymmetry coefficient $($ AC) & 0.27 & 0.06 & & -0.50 & -0.78 \\
Standard error of AC & 0.52 & 0.52 & & 0.52 & 0.52 \\
Kurtosis $(K)$ & -0.59 & -0.88 & & 0.82 & -0.24 \\
Standard error of $K$ & 0.92 & 0.92 & 0.92 & 0.92 \\
\hline
\end{tabular}

one-group, pretest-posttest design, it appears that the learning opportunities designed using the SL-CT framework were effective influences on these participating students' SL and CT. However, the limitations prevent unquestioned attribution to the lesson design since no random comparison/control group results were available. Therefore, analysis of the associated qualitative data might help inform and support the claim of influence.

The students' written work showed a considerable progressive improvement in the comprehensive use of scientific knowledge and the use of CT abilities, which became increasingly more effective. The use of $\mathrm{CT}$ abilities related to making and judging inferences when communicating and arguing about societal issues were emphasized at the grade 6 level. The content analysis revealed less well-developed use of scientific knowledge and CT at the beginning compared to later in the study. The examples of student responses and justifications below illustrate answers given to a question in an activity at the beginning of the intervention, which demonstrate superficiality and circularity.

Could the following human activities contribute to a change in the natural composition of the atmospheric air? (Write "Yes" or "No" for each option, justifying your choice).

Could the following human activities contribute to a change Yes or No Why? in the natural composition of the atmospheric air?

$\begin{array}{lll}\begin{array}{l}\text { Travelling on foot } \\ \text { Travelling by car }\end{array} & \text { No } & \begin{array}{l}\text { Because it doesn't cause pollution } \\ \text { Because it causes pollution }\end{array} \\ \begin{array}{l}\text { Could the following human activities contribute to a change } \\ \text { in the natural composition of the atmospheric air? }\end{array} & \text { Yes or No } & \text { Why? } \\ \begin{array}{l}\text { Travelling on foot } \\ \text { Travelling by car }\end{array} & \text { Yes } & \begin{array}{c}\text { It causes no damage to the } \\ \text { atmospheric air }\end{array} \\ \text { To } & \text { Pollutant (why) }\end{array}$


Student responses and justifications became more in-depth when explaining scientific phenomena later in the intervention, as shown in the following examples from the same student.

\begin{tabular}{|c|c|c|c|}
\hline \multicolumn{2}{|c|}{$\begin{array}{l}\text { Could consuming polluted water provoke } \\
\text { the following disease? }\end{array}$} & \multicolumn{2}{|c|}{$\begin{array}{l}\text { Could the following risk factors be associated } \\
\text { to cardiovascular disease? }\end{array}$} \\
\hline Disease & Yes or No? Why? & Factor & Yes or No? Why? \\
\hline Diabetes & $\begin{array}{l}\text { No, because diabetes is } \\
\text { "caused" by the exaggerated } \\
\text { consumption of lipids and } \\
\text { carbon hydrates. Polluted } \\
\text { water does not have lipids } \\
\text { nor carbon hydrates. }\end{array}$ & Smoking habits & $\begin{array}{c}\text { Yes. Because smoking causes blood } \\
\text { vessels to be become thick, not } \\
\text { permitting the passage of blood } \\
\text { in the blood vessels. (This can ...) }\end{array}$ \\
\hline Diarrhea & $\begin{array}{l}\text { Yes, because diarrhea (can be) } \\
\text { is caused by microbes that } \\
\text { enter our organism; polluted } \\
\text { water has these microbes. }\end{array}$ & Inadequate diet & $\begin{array}{l}\text { Yes. Because fat, salt, and sugar in } \\
\text { excess accumulate only in blood } \\
\text { vessels, provoking thickening of } \\
\text { the blood vessels; vegetables are } \\
\text { also necessary because of the } \\
\text { vitamins and minerals that are } \\
\text { necessary for the organism (because }\end{array}$ \\
\hline
\end{tabular}

Throughout the intervention, students' oral and written responses to questions integrated in the learning experiences showed increasing improvement and use of thinking abilities in conjunction with the mobilization of scientific knowledge to engage socioscientific ideas. The excerpts below from one student's responses illustrate improvement in the use of knowledge and scientific evidence in effectively mobilizing CT abilities related to arguing and communicating at three points in the SL-CT lessons on healthy diets.

Example 1 (around the beginning of the intervention)

\section{Opinion}

It is my opinion that this menu is: Satisfactory

because, there are some negative aspects, such as the chicken lasagna as it contains a lot of fat which is saturated and the ice cream for the same reason. However as I choose the classification "Satisfactory" I know that there are also some positive aspects, such as water, which is essential to our life, cantaloupe which is a fruit and we need this since it is the second largest sector in the Food Wheel.

\section{Example 2 (around the middle of the intervention)}

\section{Debate (preparation)}

Question: Do you agree or not with the closure of the school bar during the lunch break?

My opinion: Yes, I agree.

The reasons that leads me to having this opinion:

I agree, because if the bar is open, there are many students that instead of having lunch in the canteen will do it there and choose to eat junk food (cookies, cakes, soft drinks, ...). Lunch of these students will be less healthier and be more expensive than in the canteen.

\section{Reasons against my opinion:}

Students may say they do not like canteen food.

\section{Refutation:}

Eating at the bar will make a healthier eating less, which can cause diseases such as obesity. 
Example 3 (near the end of the intervention)

\author{
Role-Play (preparation) \\ Question: The Mayor should or not defend the installation of a cement factory in Vale Maior? \\ Role: \\ resident of that village \\ Position and Reasons (argumentation): \\ I'm against it because in towns and villages where the cement factories have been \\ installed there has been an increase in the number of persons residing nearby \\ affected with respiratory diseases, mainly workers of the cement factory. Although \\ the cement factory increases employment, I am against it because I value people's \\ health. There are data suggesting that the cement factories destroy soils and this \\ will also decrease the land for agriculture and thereby further affect air quality \\ due to the decrease in the number of plants in the village.
}

The first example revealed little emphasis on the argument although the student does demonstrate the intention of being argumentative; in example 2, there are arguments based on scientific information, which are expressed using appropriate language. Example 3 showed the use of reasons relating to different aspects, namely, economic, environmental, and personal health. Also evident are the consideration of implications and consequences based on scientific information and the compare and weigh reasons in defense of the inherent role position.

After implementation of the learning experiences developed using the CT/SL framework, the average levels of CT and SL reached by students were significantly higher than those obtained before the intervention. Content analysis of the students' work, within the learning experiences deployed, showed that there had been improvement in the target CT and SL areas of mobilization of scientific knowledge and in the use of thinking abilities, in particular, making inferences, presenting an argument, and communicating effectively about socioscientific ideas.

\title{
Conclusions and Implications
}

The results support the conclusion that the learning experiences developed and implemented - focused on $\mathrm{CT}$ and aiming for SL for teaching and learning sciencecontributed to the improvement of CT and SL levels of the students involved in this study. Despite the limitation of the absence of a control group, after the implementation of these innovative learning experiences in the science classes, the average CT and SL levels were significantly higher than those obtained at the start of the intervention. Thus, promoting students' CT and SL requires adequate learning experiences that create multiple and diverse opportunities for students to mobilize elements or aspects emerging from CT and SL, namely knowledge and CT abilities. At this level, the framework is configured as a relevant aid in fundamentally and explicitly developing learning experiences directed toward CT/SL and able to support science teaching practices more in line with the goals of critical SL, ensuring that all students develop abilities and knowledge relevant not only to the pursuit of their studies but also to operate effectively in their personal life, the labor market, and a pluralistic democratic, scientific, and technologically advanced society as active citizens and agents of social cohesion. As it has been repeatedly stressed in documents of international reference, science education should equip every citizen with the skills needed to live and work in 
a world that is rapidly changing, giving them the opportunity to develop CT and scientific reasoning that will enable them to participate in informed decisions and courses of action that affect their well-being and the welfare of society and the environment (Harlen, 2010; ICSU, 2011; Osborne \& Dillon, 2008; Rocard et al., 2007).

In this context, the appropriation of $\mathrm{CT} / \mathrm{SL}$ rationales, learning experiences, and resources that are anchored on those rationales seems to be of great relevance for the TR. The CT/SL framework could help other teachers identify and then efficiently and effectively change their science teaching practices, seeking to promote SL by improving the quality of science education. Thus, professional development opportunities for teachers must be offered, including the creation of learning networks or communities where teachers can engage in cycles of thought and action, so that classroom practices are coherent and consistent with current international guidelines for science education, in particular, compulsory education.

Acknowledgments The authors thank Dr. Larry Yore and Mrs. Sharyl Yore for their mentoring assistance.

\section{Appendix}

Table 2

Table 2 Learning experiences, underlying topics, and CT/LS elements required

\begin{tabular}{|c|c|c|}
\hline Topic & Learning experience & $\mathrm{CT} / \mathrm{SL}$ elements required \\
\hline \multirow[t]{5}{*}{$\begin{array}{c}\text { Food and } \\
\text { health }\end{array}$} & \multirow[t]{3}{*}{$\begin{array}{l}\text { Written work: critical assessment of (a) menus } \\
\text { from different restaurants (vegetarian, macro } \\
\text { biotic, fast food, pizza, steak houses, ...) and } \\
\text { (b) shopping lists of food products (for } 1 \text { day, } \\
\text { a weekend, } 1 \text { week, ...) }\end{array}$} & $\begin{array}{l}\text { Rebuilding and using scientific knowledge } \\
\text { on nutrients as food constituents, the } \\
\text { main function(s) of each nutrient in the } \\
\text { human body, consequences to health } \\
\text { resulting from the presence of a given } \\
\text { nutrient in excess or shortage in the } \\
\text { human body, principles of a healthy diet } \\
\text { and criteria for rationally deciding how } \\
\text { and what food to eat, diseases and eating } \\
\text { disorders }\end{array}$ \\
\hline & & $\begin{array}{l}\text { Using knowledge on research in science } \\
\text { (scientific practices) }\end{array}$ \\
\hline & & $\begin{array}{l}\text { Arguing and communicating, in writing, a } \\
\text { personal opinion on menus from } \\
\text { different restaurants, supplying valid } \\
\text { arguments with clarity and precision }\end{array}$ \\
\hline & \multirow[t]{2}{*}{$\begin{array}{l}\text { Debate: "Do you agree or not that the school } \\
\text { bar should be closed during lunch hour?" }\end{array}$} & $\begin{array}{l}\text { Rebuilding and using scientific knowledge } \\
\text { on nutrients as food constituents, main } \\
\text { function(s) of each nutrient in the human } \\
\text { body, consequences to health resulting } \\
\text { from the presence of a given nutrient in } \\
\text { excess or shortage in the human body, } \\
\text { principles of a healthy diet and criteria } \\
\text { for rationally deciding how and what } \\
\text { food to eat, diseases and eating disorders }\end{array}$ \\
\hline & & $\begin{array}{l}\text { Using knowledge on research in science } \\
\text { (scientific practices) }\end{array}$ \\
\hline
\end{tabular}


Table 2 (continued)

Topic Learning experience $\quad$ CT/SL elements required

Letter to the headmaster: improving the food supply at school (at the canteen and bar)

Case studies: study and discussion of a case of obesity and a case of anorexia (ways of presenting each case: newspaper article and film)
Orally argue and communicate a position on the question in debate, supplying with clarity and precision valid arguments that support the judgment made, correctly and appropriately mobilizing relevant scientific knowledge

Seriously listen to and consider other points of view, interact with others arguing and counter-arguing based on scientific evidence

Rebuilding and using scientific knowledge on nutrients as food constituents, main function(s) of each nutrient in the human body, consequences to health resulting from the presence of a given nutrient in excess or shortage in the human body, principles of a healthy diet and criteria for rationally deciding how and what food to eat, diseases and eating disorders: causes, consequences, and prevention measures

Using knowledge on research in science (scientific practices)

Deciding and assessing a course of action (defining the problem, identifying and interpreting relevant information, considering alternatives, establishing and applying criteria for the assessment of alternative solutions, deciding what should be done and why)

Communicating in writing to the headmaster a personal position and the plan of action proposed to improve the food provided at school (at the bar and canteen), explaining the course of action to be taken with clarity and precision, adducing the reasons that support it

Rebuilding and using scientific knowledge on nutrients as food constituents, main function(s) of each nutrient in the human body, consequences to health resulting from the presence of a given nutrient in excess or shortage in the human body, principles of a healthy diet and criteria for rationally deciding how and what food to eat, diseases and eating disorders: causes, consequences, and prevention measures

Using knowledge on research in science (scientific practices) 
Table 2 (continued)

\begin{tabular}{lll}
\hline Topic & Learning experience & CT/SL elements required
\end{tabular}

\section{Digestive system} and health

\section{Laboratory activities: answer each problem-question: What is the effect of saliva in the digestion of starch? How does gastric juice behave? How does bile behave?}

Analysis of newspaper articles: alcohol consumption and liver disease

Plan of action: "What can I do to preserve and/or improve the well-functioning of my digestive system?"
Respiratory system Argumentative essay: "Do you agree or and health disagree with the use of images of people smoking on television?"
Present and justify a position, decision, or plan of action regarding the case study analyzed

Rebuilding and using scientific knowledge on human life processes, organs and glands of the human digestive tract and their function(s)

Using knowledge on research in science (scientific practices)

Outlining experimental research in response to a problem-question and testing predictions; collecting, organizing, and interpreting data; drawing conclusions based on the data collected

Rebuilding and using scientific knowledge on human life processes, organs and glands of the human digestive tract and their function(s), favorable practices and conditions for digestion and proper functioning of the digestive system

Using knowledge on research in science (scientific practices)

Analyzing and interpreting data on alcohol consumption and the incidence of liver disease (alcoholic): organizing quantitative information, making tables, graphs, and diagrams; seeking patterns; drawing and communicating conclusions; identifying and assessing courses of action

Rebuilding and using scientific knowledge on human life processes, organs and glands of the human digestive tract and their function(s), favorable practices and conditions for digestion and proper functioning of the digestive system

Using knowledge on research in science (scientific practices)

Deciding on and assessing courses of action: defining the problem, identifying and interpreting relevant information, considering alternatives, establishing and applying criteria for the assessment of alternative solutions, deciding an action based on rational reasons

Rebuilding and using scientific knowledge on human life processes, organs in the respiratory system and their function(s), favorable practices and conditions for lung function and well-functioning of 
Table 2 (continued)

Topic Learning experience CT/SL elements required

Role-play/simulated case: "The Mayor should or not defend the installation of a cement factory in Vale Maior?"

Analysis of medical examinations (laboratory and/or imaging tests) the respiratory system, consequences of smoking on the lung function

Using knowledge on research in science (scientific practices)

Arguing and communicating in writing, expressing the thesis defended (in agreement or disagreement), supplying with clarity and precision valid supporting arguments, correctly and adequately mobilizing relevant scientific knowledge

Seriously consider reasons in favor of the opposite point of view and refute them

Rebuilding and using scientific knowledge on factors (sources of pollution and pollutants) responsible for the change in air quality, consequences on lung function

Using knowledge on research in science (scientific practices)

Taking on and creating a role in a simulated case/performance of roles on a given question, orally argue and communicate a position on the question in debate, explaining with clarity and precision valid arguments that support the judgment made, correctly and appropriately mobilizing relevant scientific knowledge

Seriously listen to and consider other points of view, interact with others arguing and counter-arguing based on scientific evidence

Rebuilding and using scientific knowledge on human life processes, organs in the respiratory system and their function(s), favorable practices and conditions for lung function and well-functioning of the respiratory system, consequences of smoking on the lung function

Using knowledge on research in science (scientific practices)

Analyzing and interpreting medical exams (arterial gasometry and chest X-rays), coming to and communicating conclusions, identifying and assessing courses of action 


\section{References}

Aikenhead, G. (1992). Logical reasoning in science and technology: An academic STS science textbook. Bulletin of Science Technology and Society, 12(3), 149-159.

Aikenhead, G. (2007, May). Expanding the research agenda for scientific literacy. Paper presented at the Linnaeus Tercentenary Symposium on Promoting Scientific Literacy: Science Education Research in Transaction. Uppsala University, Sweden. Available from http://www.usask.ca/education/profiles/ aikenhead/webpage/expand-sl-res-agenda.pdf

American Association for the Advancement of Science (1990). Science for all Americans: Project 2061. New York, NY: Oxford University Press.

American Association for the Advancement of Science (1993). Benchmarks for science literacy: Project 2061. New York, NY: Oxford University Press.

BSCS. (2008). Scientists and science education. Retrieved from http://science.education.nih.gov/SciEdNation. nsf/EducationToday1.html.

Council of Ministers of Education, Canada (1997). Common framework of science learning outcomes, $K$ to 12: Pan-Canadian protocol for collaboration on school curriculum. Retrieved from http://www.cmec.ca/ Publications/Lists/Publications/Attachments/177/pancan-protocol-collaboration-1997.pdf

Coutinho, C. (2011). Metodologia de investigação em ciências sociais e humanas [Methodology of research in social sciences and humanities]. Coimbra, Portugal: Almedina.

Department for Education (2011). Review of the National Curriculum in England. What can we learn from English, mathematics and science curricula of high-performing jurisdictions. Retrieved from https:/www.gov.uk/government/uploads/system/uploads/attachment_data/file/ 197636/DFE-RR178a.pdf

Department for Education (2013). National Curriculum to England (framework document). Retrieved from https:/www.gov.uk/government/uploads/system/uploads/attachment_data/file/339805/MASTER_final_ national_curriculum_until_sept_2015_11_9_13.pdf

Ministerial $\bar{C}$ ouncil on Education, Employment, Training and Youth Affairs (2006). National assessment program-Science literacy year 6. School release materials. Author. Retrieved from http://www.scseec. edu.au/archive/Publications/Publications-archive.aspx\#measuring

Ennis, R. H. (1987). A taxonomy of critical thinking dispositions and abilities. In J. B. Baron \& R. J. Sternberg (Eds.), Teaching thinking skills: Theory and practice. New York, NY: W. H. Freeman.

Ennis, R. H. \& Millman, J. (1985). Cornell critical thinking test, level X. Pacific Grove, CA: Midwest.

Finnish National Board of Education (2004). National core curriculum for basic education. Retrieved from http://www.oph.fi/english/sources_of_information/core_curricula_and_qualification_requirements/basic_ education

Ford, C. L. \& Yore, L. D. (2012). Toward convergence of metacognition, reflection, and critical thinking: Illustrations from natural and social sciences teacher education and classroom practice. In A. Zohar \& J. Dori (Eds.), Metacognition in science education: Trends in current research (pp. 251-271). Dordrecht, The Netherlands: Springer.

Hackling, M. W., Goodrum, D. \& Rennie, L. (2001). The status and quality of teaching and learning of science in Australian schools. Canberra, Australia: Department of Education, Training and Youth Affairs.

Harlen, W. (2006). ASE guide to primary science education. Hatfield, England: Association for Science Education.

Harlen, W. (Ed.). (2010). Principles and big ideas of science education. Hatfield, England: Association for Science Education.

Hatcher, D. \& Spencer, L. A. (2000). Reasoning and writing: From critical thinking to composition. Boston, MA: American Press.

Hofstein, A., Eilks, I. \& Bybee, R. (2011). Societal issues and their importance for contemporary science education-A pedagogical justification and the state-of-the-art in Israel, Germany, and the USA. International Journal of Science and Mathematics Education, 9, 1459-1483.

International Council for Science (2011). Report of the ICSU ad-hoc review panel on science. Paris, France: Author. Retrieved from http://www.icsu.org/publications/reports-and-reviews/external-review-of-icsu

Lin, S.-S. (2014). Science and non-science undergraduate students' critical thinking and argumentation performance in reading a science news report. International Journal of Science and Mathematics Education, 12, 1023-1046.

Millar, R. \& Osborne, J. (1998). Beyond 2000: Science education for the future. London, England: King's College School of Education.

Ministério da Educação e Ciência (2013). Metas curriculares [Curricular goals]. Lisbon, Portugal: Author. 
National Research Council (1996). National science education standards. Washington, DC: National Academies Press.

National Research Council (2012). A framework for K-12 science education: Practices, crosscutting concepts, and core ideas. Washington, DC: National Academies Press.

NGSS Lead States (2013). Next generation science standards: For states, by states. Washington, DC: National Academies Press. Available from http://nextgenscience.org/next-generation-science-standards.

Norris, S. \& Ennis, R. H. (1989). Evaluating critical thinking. Pacific Grove, CA: Critical Thinking Press \& Software.

Oates, T. (2010). Could do better: Using international comparisons to refine the national curriculum in England. Retrieved from http:/www.education.gov.uk/inthenews/inthenews/a0068191/could-do-betteranalysis-of-international-curriculums-published.

Organisation for Economic Co-operation and Development (2006a). Assessing scientific, reading and mathematical literacy - A framework for PISA 2006. Paris, France: Author.

Organisation for Economic Co-operation and Development (2006b). Evolution of student interest in science and technology. Policy report. Paris, France: Retrieved from http://www.oecd.org/dataoecd/16/30/ 36645825.pdf

Organisation for Economic Co-operation and Development (2009). PISA 2009 assessment framework—Key competencies in reading, mathematics, and science. Paris, France: Author.

Osborne, J. \& Dillon, J. (2008). Science education in Europe: Critical reflections. London, England: Nuffield Foundation. Retrieved from http://www.nuffieldfoundation.org/sites/default/files/Sci_Ed_in_Europe_ Report_Final.pdf.

Roberts, D. A. (2007). Scientific literacy/science literacy. In S. K. Abell \& N. G. Lederman (Eds.), Handbook of research on science education (pp. 729-780). Mahwah, NJ: Lawrence Erlbaum.

Rocard, M., Csermely, P., Jorde, D., Lenzen, D., Walberg-Henriksson, H. \& Hemmo, V. (2007). Science education now: A renewed pedagogy for the future of Europe. Luxembourg, Belgium: European Commission. Retrieved from http://ec.europa.eu/research/science-society/document_library/pdf_06/ report-rocard-on-science-education_en.pdf.

Scriven, M. \& Paul, R. (2007). Defining critical thinking. Retrieved from http://www.criticalthinking.org/ aboutCT/define_critical_thinking.cfm.

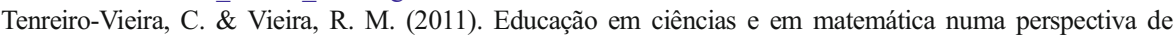 literacia: desenvolvimento de materiais didácticos CTS / Pensamento Crítico (PC) [Mathematics and science education for literacy]. In W. dos Santos \& D. Auler (Eds.), CTS e educação científica: desafios, tendências e resultados de pesquisas (pp. 417-437). Brasília, Brazil: Editora Universidade de Brasília.

Vieira, R. M. (1995). O desenvolvimento de courseware promotor de capacidades de pensamento critico [The development of a courseware to promote critical thinking abilities] (Unpublished master's thesis). University of Lisbon, Portugal.

Vieira, R. M., Tenreiro-Vieira, C. \& Martins, I. (2011). Educação em ciências com orientação CTS [Science education with STS orientation]. Porto, Portugal: Areal Editores.

Yore, L. D. (2012). Science literacy for all-More than a slogan, logo, or rally flag! In K. C. D. Tan \& M. Kim (Eds.), Issues and challenges in science education research: Moving forward (pp. 5-23). Dordrecht, The Netherlands: Springer.

Yore, L. D., Pimm, D. \& Tuan, H.-L. (2007). The literacy component of mathematical and scientific literacy. International Journal of Science and Mathematics Education, 5, 559-589. 